\title{
Strategic competence as a core of business translator's qualification
}

\author{
Tetiana Andrienko ${ }^{1 *}$, Iryna Shpeniuk ${ }^{2}$ \\ ${ }^{1}$ Westcliff University, Irvine, 17877 Von Karman Ave \#400, Irvine, California, USA 92614 \\ ${ }^{2}$ Institute of International Relations, Taras Shevchenko National University of Kyiv, 64/13, \\ Volodymyrska Street, City of Kyiv, Ukraine, 01601
}

\begin{abstract}
Based on the interactional translation model, this paper discusses the role of translator's competence in the success of translation for business. Via complex analysis of translations of advertising texts as discourse acts that are pragmatically oriented and relatively uniform in their aims, the authors establish an extralingual criterion for measuring the quality of their translation - the ability to satisfy the same cognitive/communicative needs and exert the same influence as the source texts on the audience with the different cultural background. Arguing that translator's /interpreter's qualifications should include awareness of the target community's ethnical and business culture coupled with the sense of responsibility for the results of translation as an intercultural discourse act, the authors formulate implications for the formation of strategic competence in teaching professional business translators.
\end{abstract}

\section{Introduction}

The vision of translation as an intentional interactional and transformational activity in which translator's role goes far beyond 'transcoding messaging' 'without losses', but instead, lies in organizing cognitive interaction between the source and target language cultures, implies a different focus in approaches to translators' education and assessment of their qualification. The traditional focus on developing strong source and target language competences along with the analysis of all types of transformations confines the prospective professionals to the language level, seldom going beyond the semantics of 'verbal signs/messages', instead of giving them a broad array of communicative and cultural competences, needed to successfully perform the cross-cultural interaction in the globalized world.

The analysis of translation failures (political, business, marketing and advertising) shows that many of them result from the lack of translators' cultural (cognitive and communicative) competence, including translations that are literally close to the original, but have a different sense and function in communication, due to conventions, politeness rules, etc. The source text (ST) is not supposed to be 'delivered unchanged' in translation. The translated (target) text (TT) should be changed to satisfy the same cognitive and communicative needs of the audience with a different worldview and cultural background, as the ST. Having established the set of translation problems and strategies to resolve them [1], we believe that translator's

\footnotetext{
${ }^{1}$ Corresponding author: tania_andrienko@ukr.net
} 
education should center around strategic competence [2], based on ethics and responsibility for the result of translation.

Globalizing world and intensifying business interactions require reconsidering the role of translator in business communication and the qualification criteria for translators. Translation for business purposes, or business translation, is a special field of translation, which is very fluid, dynamic, and associated with immediate economic results. In essence, this field is very demonstrative in terms of practical expectations of a translator/interpreter and criteria of the success of translator's work.

In the business world, there is a growing demand for translation [3, para 5], along with the growing recognition of the importance of translation for success in business. According to 2018 estimate, "annual enterprise spending on translation services is expected to grow to US $\$ 45$ billion by 2020 , primarily driven by increasing globalization and an increasing amount of text being generated worldwide"[Ibid., para 7].

Focusing on translation for business purposes, researchers associate the quality of translation with the success in business: "High-quality translation of corporate promotional materials which consist of printed advertisement, corporate profile, product introduction, etc. can help a company establish a good image and promote sales in the target market" [4]. Business translation is viewed as "a special category of translation with distinctive features and requirements" [5].

Research focus on extralingual purposes and results of translation clearly manifests limitations of the traditional criterion of translation equivalence as the indicator of its quality. The role of translation in promoting business purposes has become especially noticeable with the growth of contacts between the countries with very different languages and distant cultures.

In particular, the studies of Chinese to English translation conclude: “... its important role in promoting the business and products of a company has been invisible and transparent for years. Influenced by traditional translation theories, translation of Chinese corporate promotional materials is widely viewed as a transfer of information from the source text (ST) to the target text (TT) and neglects the two languages' differences at the linguistic and cultural levels. As a result, the English translation of some Chinese corporate promotional materials are difficult to understand and even unacceptable in the eyes of English readers". [4, emphasis added - T.A., I.Sh.]

The observed clash between the practical expectations of business translations, and theorizing about 'information transfer' with 'maximum similarity', as the equivalence, the major indicator of translation quality, has been viewed for decades, suggests the need of "rethinking equivalence": "We conclude by advocating that the translation process be reframed as a process of intercultural interaction, rather than a lexical transfer of meaning" [6, emphasis added - T.A., I.Sh.]. The problem to be studied is the criteria of successful translation for business, and measurement of quality of such translation. Therefore, the aim of this paper is to elucidate the criteria of success in business translation and establish the qualitative indicators of such translation.

The analysis of successes and failures in intercultural business interaction raises research questions which we will attempt to solve in this paper:

- What are the criteria of translation quality/success, as related to the purpose of translation for business?

- What are the translator's /interpreter's qualifications and characteristics needed to work successfully in the business setting?

\section{Theoretical Foundations}


The idea that the text concept is supposed to undergo changes in translation is not new. In his Experience in Translation subtitled in Italian "Saying almost the same thing", U. Eco formulated the idea that translation involves a shift between cultures and is about making the text understandable to a different language reader [7]. "The faithful translator must choose a 'linguistic unfaithfulness' which guarantees the textual one" [8].

Being a highly pragmatically oriented activity, business translation calls for broadening theoretical horizons. As a result of interpretive content analysis of qualitative and quantitative cross-language studies published in core International Business journals over the course of a decade, A. Chidlow at al. established "the dominance of a technicist view of translation associated with the equivalence paradigm" [6]. They conclude:

"IB [International business] researchers are often operating in highly multilingual contexts which are still not well understood even in fields such as translation studies. In these 'inbetween spaces', in which hybrid forms of language develop and a high degree of linguistic improvisation can often be seen, we would anticipate that there is considerable potential for novel theorizing". [Ibid., emphasis added - T.A., I.Sh.].

Most of the studies of translation for business adopt the Scopos theory [9] as the most appropriate theoretical basis since it focuses on recreating the function of the source text in translation.

The said theory is viewed as an appropriate theoretical basis for resolving translation problems when very differing corporate and communication cultures are in contact: "Skopos theory proposes that translations are done to fulfill a target-side purpose and the translator's work is a mode of communication that is cross-cultural and mediated, which shifts the focus of translation studies from decoding the meanings from ST and encoding those meanings into TT to the realization of functions of TT" [4]. "With the functional rules and principles, the Skopos theory becomes the effective guidance of business English translation" [5].

Functionalist approach to translation is also based on Scopos as its theoretical basis, but with the account of the styles of the contacting languages: "Under the guide of functionalist theory, the function which the target text achieves should be equal to the source text. To make the translation realize its skopos and achieve its functions, the translator should first be clear about the different linguistic styles of the two languages and their contexts" [10].

Analyzing Chinese-to-English translations, theorists conclude that "a word-for-word translation of the Chinese text [...] judged by its communicative skopos, can't be a good one. Foreign readers may not be very interested in how a business group in China is inspected by governmental officials or its CEO's interview with a political leader. They would like to find from the company's profile some objective information such as its competitiveness, product quality and so on. If they want to know whether a company is worth doing business with, they prefer to refer to comments from people of the same trade rather than a company's relationship with governmental officials" [4].

As we see from this analysis, translation problems do not arise solely out of language or ethno-cultural differences: business and political cultures, systems of values and scopes of interests of the SL (source language) and TL (target language) communities exert a noticeable influence on transformation of the original concept in translation. Therefore, in our opinion, the relevant methodology for analyzing business translation should be cognitive in its nature and base on the account of business and ethnical cultures. Such methodology is provided by the interactional translation model [1], which is based on interactional communication model $[11,12]$.

Interactional vision of communication is different from its traditional model as transmission of messages [13]. According to the interactional communication model, "The reality of communicative exchanges, anyhow, does not display any transmission; linguistic interactions constitute joint activity which leads to some sort of 'echoing response' in the recipient's mind. The response is practically never absolutely similar, but subject to variation 
due to situational and personality factors. Communication is behavioral coordination in the domain of social coupling and consensual interaction" [12].

Thus, what occurs in communication, is not the transmission or exchange of messages, which are transferred between the speaker and the hearer unchanged, but the joint construction of cognitive objects, where the hearers create in their mind certain concepts, based partially on sign messages received from the sender, and partially on their own cognitive structures and interpretational frames: "information is generated (reproduced) by the receiver who interacts with the sender" [Ibid.].

The interactional translation model presents translation as the interaction between the author, translator and recipient, with the translator being the central figure, who organizes and controls the communication taking responsibility for its results. The translator's activity is guided by the translation strategy aimed at transforming the concept of the original text, with the view to making it perceivable for the target audience, and guiding their perception in a desirable way. The measure of translation quality in the interactional paradigm is not its equivalence, but satisfying the same cognitive and communicative needs of the target audience [1].

To study the criteria of success in business translation and establish the qualitative indicators of such translation, interactional translation model appears to be the relevant theoretical basis as it focuses not only on the propose of communication, but on its extralingual result - the appropriate perception of, and reaction to the translated business discourse. Secondly, it opens the perspective of analyzing strategies effective in business translation.

The need of teleological focus and target reader-oriented approach ("catering to the customers' needs" [5] is confirmed by other researchers: "... it requires the translator to be target-reader oriented during translation process. In the process of translating business English contracts, their target functions should be in line with the project initiator's or the client's purpose or intention" [10]. Another essential aspect is an account of cultural differences. "In translation, to realize the ideal textual conversion from source language to target language, translators must have cross-cultural mindset and be target-cultureoriented" [5]. If the translator takes no note of the target language and culture, the translation may seem odd to the target audience and cannot attract their attention and thus will fail to promote sales [Ibid.].

Studying translation as the cross-cultural communicative interaction, we view the translator not as a transcoder or transmitter of messages, but as an organizer, manager and strategizer of a communicative/discourse act. Translator's activity is guided by a global strategy, which determines the change of the whole text concept, and local strategies, which govern the translation of high entropy fragments of the text.

\section{Methodology}

As the material to study translation for business, we selected advertising texts. This choice was determined by two factors: (1) pragmatic uniformity of these texts, as the aim they are pursuing is rather obvious although usually oblique (they are indirect discourse acts): injunction for the consumer to choose/buy a certain service or product; (2) heavy reliance of advertising texts on cultural conventions, values, preferences, which creates challenges for translation.

To study the criteria of success in translation for business and measure the quality of translation, we implemented a complex methodology combining comparative and descriptive methods. We used a comparison of business advertising texts in the original and in translation to establish differences in their cognitive, semantic, structural and pragmatic aspects. Descriptive methods included pragmatic (intentional) analysis, cognitive analysis of the 
source and target referential domains of metaphors/metonymies in the source and target texts, and the analysis of extralingual and cultural factors involved in the perception and interpretation of the advertising.

Each advertising text was analyzed as a complex and complete discourse act [14] in the entirety of its verbal and non-verbal features, in terms of cultural appropriateness and effectiveness with the target audience. The analysis of the communication context was implemented to establish the cognitive foundations and communicative prerequisites of the discourse act. The results were summarized and implications for practical translation and teaching professional translators were formulated.

\section{Results and discussion}

The choice of advertising materials for the analysis of business translation is determined by an array of its specific features:

(1) Uniformity of its function in business operations,

(2) Functional syncretism of each advertising text: "Advertisement is a prominent form of business promotion. A company resort to advertisements to inform, to persuade and to remind customers of their products and services [5].

(3) Pragmatic orientation towards the target consumer's response: "Since it is important to meet the expectation of the target language consumers as to what message the advertisement delivers, the evaluation of advertisement translation relies completely on the target audiences' responses" [Ibid.].

(4) Complexity of the cognitive plane resulting from the interaction of cultural senses, verbal and non-verbal messages, and context-dependence.

Each discourse act includes context as its necessary informational background. Understood in the broadest sense after R. Jacobson $[13,15]$, the communication context includes all situational and textual factors essential for the realization of the discourse act. In the intercultural discourse act, which takes place in the case of translation, the situational factors, even such as physical distance, time, and deictic markers acquire a different status and become the markers between the source and target cultures. The difference between highcontext and low-context cultures [16] predetermines the degree of explicitness deemed appropriate in a specific culture. The differences of values, metaphorical mappings [17], interpretations and associations in different cultures suggest that making an equivalent translation, rendering the ideas as close to the original as possible will hardly result in the satisfactory perception and required pragmatic impact of advertising texts.

The translation for business is expected to "cater to the customers' needs" [5], which means tailoring the whole discourse act to the contextual basis of the target reader. Thus, for less technically advanced populations, technical instructions tend to be much more detailed in translation, to suggest the reader the same course of action in the ways they can understand.

In the case of advertising, the expected response of the target audience should be the consumption of the same goods/services. The fidelity of translation in this case may be measured by the audiences' perception of the appeal encoded in the advertising. Aiming at such equivalence of the effect, the translator may choose to, based on the values prevailing in the target culture, change cognitive structures and metaphoric patterns, types of speech acts and respectively, sentence structures, etc.

Some examples where the advertising did not work as expected exemplify the failures of translations done close to the text, disregarding cultural, cognitive and pragmatic differences:

(1) Pepsodent tried to sell its toothpaste in Southeast Asia by emphasizing that it "whitens your teeth." They found out that the local natives chew betel nuts to blacken their teeth which they find attractive [18]. 
In this case European creators of the advertising relied on their own values (white teeth as a sign of beauty, which is a positive value), instead of considering the values of a different culture (e.g., health) to use as a basic argument in their advertisement.

(2) A company advertised eyeglasses in Thailand by featuring a variety of cute animals wearing glasses. The ad was a poor choice since animals are considered to be a form of low life, and no self-respecting Thai would wear anything worn by animals [Ibid.]

This ad required cultural adaptation rather than translation. In the minds of Europeans, animals arouse warm and positive associations with nature, childhood, etc., and create the attractor for prospective buyers. To achieve the same pragmatic aim of presenting their good as appealing, the localizers of the ad were to follow a global domesticating strategy and choose the images that conceptualize positive values for the Thai, to create a pragmatically equivalent effect of the advertising based on another metaphorical mapping or association.

As we see from the examples above, cultural blunders around advertising in other countries involve not so much language issues, as cognitive structures including values, beliefs, standards of beauty, mappings of the world etc.

The next example involves a difference in using codes - symbolic or non-symbolic use of graphical signs:

(3) When Gerber, a Nestle owned purveyor of baby foods first started selling their baby

food in Africa, they used the same packaging as in the USA - with the cute baby on the

label. Later they found out that in Africa companies routinely put pictures on the label of what is inside the package, since most people cannot read [19].

The failures in business communication abroad become subject of numerous professional and scholarly discussions, since ineffective advertisings usually result in losses of profits and ultimately the collapse of business. The examples analyzed above show that, the qualification of a business translator should include a thorough awareness of the target community's local values, beliefs, stereotypes and superstitions, as well as interpretational frames they will be using to internalize the information 'transmitted' by the ad.

The language differences are also frequent reasons of poor advertising campaigns [20; 21]. The failures may be grouped into several categories (in each case, however, it will be obvious, that the failure of advertising is rooted mainly in the cognitive field).

Let us analyze some examples, which prove that using standard approaches (e.g., 'names should be transcribed or transliterated'), instead of thinking strategically with the account of broad context and cultural background, may result in blunders, in the cases below phonetically compromising:

(4) When Coca-Cola entered the China market, they named their product something that when pronounced, sounded like, "Coca-Cola". The only problem was that the characters used meant "Bite the Wax Tadpole". When they learned of their blunder, they later changed to a set of characters that mean "Happiness in the Mouth" [Ibid.].

(5) Gerber, the baby food company, has a problem in France, where "Gerber" translates as "vomit." [Ibid.].

(6) The brand name "Blue water" was transcribed in Ukrainian as "Блю Воте” (which sounds like "vomit" in Ukrainian), thus arousing a rather unpleasant association.

Based on the interactional translation model, we believe that translations of advertising texts should be governed by translation strategy aimed at creating an advertisement, which would be equally appealing and impactful. Global strategy determines what the final result is expected to be in its entirety combining denotative, associative and evaluative aspects [22] of the integrative text concept. This may include associative images, basic positive and negative assumptions of the society, recent or historical events of significance, etc.

Local translation strategies are enacted to resolve specific translation problems: factual or cognitive realia, metaphorical mappings, puns or sound imitations etc.

Some examples below exemplify more or less successful choices of translation strategies: 
(7) McDonald's learns when not to translate its slogan.

In 2003, McDonald's launched one of its most memorable ad campaigns to date in 120 different countries and 20 languages. The "I'm Lovin It" slogan became a staple for the global brand that year but it had mixed results overseas when it came to translating the campaign that worked so well in English-speaking markets.

Some translations hit the mark but there were a few awkward results in Ukraine, France and Germany [23].

Analysts believe that the reason of failure was that McDonald's ... decided not to use a creative translation for countries considered to have relatively high English literacy levels [Ibid.]. In our terms, the initiator of translation - McDonald's - chose foreignising strategy with the hope that the 'foreignness' of the slogan will be understood, and moreover, will add value in the markets like Ukraine, where everything 'pro-western' is marked as a positive value.

Ukrainian translation of 'I'm Lovin' It' is 'Мені ие подобається' [24]

Although the choice of the global translation strategy is logical in this case, the local strategies seemed to ignore much more specific reference of It (to Mc Donald's) than Ukrainian "ue", as well as the emphatic (Continuous tense of 'love') and colloquial connotations of the phrase. The result appeared to be considerably weakened and ambiguous, and therefore not as effective as the original slogan. A later translation "Я це люблю" returned the slogan a certain degree of its original expressiveness.

Even when the cultures are not too distant, or intensive cultural exchanges have formed cultural awareness, when the choice of foreignising strategy for the advertisement of foreignmade goods appears appropriate, ignoring local strategies of form (to render pun, metaphor etc) results in literal translations which make the slogans less appealing. For example,

(8) I'd Walk a Mile for a Camel. - Заради Camel можна подолати будь-яку відстань [Ibid.]

The original slogan contains at least two puns built on 'walk a mile' being simultaneously a free word combination and a part of idiom "walk a mile in someone else's shoes", and polysemy of the preposition 'for' - "in order to get something" and "instead of somebody". As a result, the original sounds funny and playful, but the translation does not.

The choice of domestication strategy for translation is evidently supposed to approximate the advertised object to the local cultural values. In the case of Ukraine with its westernoriented values and high awareness of European cultures, this choice does not appear to be justified.

As another example, Volkswagen's legendary "Think Small" campaign for Beetle in its time overturned the minds of car-buyers who at that time were offered cars praised for their speed, size, design and other features all car-makers tried to compete for. "With their legendary "Think Small" campaign, DDB did the exact opposite of what every other car ad was doing: They were brutally, boldly and cleverly honest. The truth was that the Volkswagen Beetle was a small, slow and ugly foreign car. By admitting that, and explaining why those were good things, DDB turned the VW Bug into an iconic piece of American pride." [25] "The low, sleek profile ... sculptured lines ... the distinguished look ... the alive, eager response..." With such impactful adjectives, you'd think this copy was meant to describe an ultramodern jet from Boeing. You'd be wrong. All of those words were pulled from an 1959 IBM ad - for a typewriter. This was the norm when Think Small first hit paper, and it's part of why VW's candor so successfully penetrated the noise [26].

The slogan VW used for its Beetle was not absolutely unpredictable (which made it stand out on the background of general advertising 'noise'), but also used pun hinting at the size of the car and simultaneously appealing to its prospective buyers who could not afford big and luxury cars via metaphor: "Do not try to solve all problems at once. Move by small steps" = 
“Think small". This combination of rightly chosen target audience, the timely appeal and unexpected presentation made both the ad and the Beetle itself a legend.

A Ukrainian translation for this slogan:

(9) Think Small - Простота довкілля [24]

The translation to some degree targets close cognitive domain: Small- Проcmoma, but the translation can hardly be traced to the car, and Beetle, in particular. All essential features and layers of the original text concept seem to be gone in translation, which means that it cannot satisfy the same cognitive and communicative needs of the audience.

Another example of domesticating attempt is the translation of Burger King's slogan:

(10) Have it Your Way. - На власний розсуд [Ibid.]

As most English language slogans, this one contains pun and may be read at least in two ways: "Have it [the burger] on your way" and "Have it [the burger] the way you like it", simultaneously sounding as an idiom to have it your [one's own] way - to do what one wants to do despite the desires, plans, etc., of other people, often disapproving [27]. The Ukrainian translation is based on the idiom, which is a phraseological counterpart of the English one, and in this sense is reasonably domesticated. But as a result, all the associations with the burger/food have disappeared, which can hardly be viewed as a faithful translation.

\section{Conclusion}

The analysis of translations of advertising texts as pragmatically oriented and relatively uniform in their discourse aims shows that the quality of such translations is assessed mainly by their ability to promote business success - the extralingual criterion associated with the ability to cater for the target audience and be as appealing as the original advertising.

Therefore, the quality of translation of advertising as a subtype of business translation should not be measured by language / semantic equivalence or proximity, but by the ability to satisfy the same cognitive/communicative needs and exert the same influence on the audience with the different cultural background.

The qualification of a business translator should include a thorough awareness of the target community's local values, beliefs, stereotypes and superstitions, as well as interpretational frames they will be using to internalize the information 'transmitted' by the ad. These qualities should be coupled with the sense of responsibility for the results of translation as an intercultural discourse act, which influence a broader course of business discourse, and ultimately - the profitability, i.e., success of business.

\section{Implications}

Making strategic decisions in business translation implies translator's responsibility for the result of the discourse act. Responsibility for the result of intercultural communication act, in our opinion, is the most important quality of a translator working in the business environment. This involves strategic competence, which is deemed central to the translator's qualification [2]. Strategic competence "correlates with the term "super-competence", performing a crucial function determining the vector of performing translation activities and affecting the course and results of these activities. Strategic competence allows one to identify translation problems and coordinate translation actions to overcome them [28].

In academic practice, several sets of knowledge and ways of thinking may be implemented/cultivated to form the translation students' strategic competence: 
- $\quad$ knowledge of International and National translation standards (ISO, GOST etc.), laws and regulations, which is necessary to form the understanding of translator's legal responsibility for the result of their translation;

- $\quad$ knowledge of translation ethics and conventions (e.g., Translators' Charter), to form ethical behaviors and attitudes;

- professional (philological) knowledge of both source and target languages, including differentiation of worldviews, understanding of cultural conventions, emotional attitudes and associations, phraseology and its roots etc.;

- understanding communicative conventions: directness/indirectness, explicitness/implicitness of expression in both languages, taboos and euphemization, emotional intelligence, mimics and body language etc.;

- rules of business turnover: meeting time/places, space symbolism, greetings, gifts (their 'phatic' function), dining traditions;

- decision making practices, distribution of authority, high/low power distance in the society;

- document turnover: using stamps/seals, electronic signatures, corporate email addresses and mail circulation and so on.

It is obvious that this list considerably exceeds the habitual scope of translator training programs. However, without the above knowledge and respective skillsets the translator's ability to take informed and often ad-hoc decisions in the course of translation for business will be considerably impaired. Hence the need to include additional courses (at least electives) or themes in translator training programs to impart the students the necessary knowledge and awareness to act competently in a business setting.

Emphasizing the importance of strategic competence in business translation, we conclude that strategic thinking is the only function inherent solely in human translation, which will never be accomplished by machine translation systems.

\section{References}

1. T. Andrienko, Strategies and tactics of translations: Cognitive-discourse aspect (based on the material of literary translation from English into Ukrainian and Russian) (Kyiv, 2016)

2. L. Chernovaty, Features of different types of translation and the content of the formation of professional competence of future translators 75 (5), 22-26 (Proceedings. Series: Philological Sciences (Linguistics), 2008)

3. V.R. Ferose, B. Pell, L. Pratt, From The Business Of Language To The Language Of Business: The Future Of Translation Worldwide URL: https://www.digitalistmag.com/future-of-work/2018/05/17/future-of-translationworldwide-06168565/

4. J. Zheng (2017). Translation of Corporate Promotional Materials in view of Skopos Theory 06, 81-88 (Journal of Arts \& Humanities, 2017)

5. L. Zhang, Business English Translation Strategies in the Perspective of Skopos: In the Case of Advertisement Translation 6, 243-246 (Open Journal of Modern Linguistics, 2016)

6. A. Chidlow, M.E. Plakoyiannaki, C. Welch, Translation in cross-language international business research: Beyond equivalence 45 (5), 562-582. (Journal of International Business Studies, 2014)

7. U. Eco, Dire quasi la stessa cosa. Esperienze di traduzione (Bompiani, Milano, 2003) 
8. Translating is: to say "almost" the same thing? URL: http://www.nannastudio.it/translating-is-interpretation-umberto-eco/

9. K. Reisse, H. Veermeer, Towards a general theory of translational action (London, Routledge, 2013)

10. Changhong Shao, Xi Li, Translation of Business Contract Text from English to Chinese in Functionalist Approach URL: https://webofproceedings.org/proceedings_series/ESSP/SSAH\%202018/SSAH_06112 24.pdf

11. H. R. Maturana, F. Varela, The Tree of Knowledge: The Biological Roots of Human Understanding (Boston, MA: Shambhala, 1992)

12. V.B. Kashkin, Telementation vs. Interaction: Which Model Suits Human Communication Best? 5, 1733-1743 (Journal of Siberian Federal University. Humanities \& Social Sciences, 2012)

13. R. O. Jakobson Closing Statement: Linguistics and Poetics (Cambridge Massachusetts: MIT Press, 1960)

14. I. Shpeniuk, Lexical Bundles as Etiquette Devices in the American Pre-Scholarly Discourse: a dissertation (Kyiv, 2016)

15. R. O. Jakobson, Linguistics and Communication Theory (The Hague; Paris: Mouton, 1971)

16. E.T. Hall, Beyond culture (New York, London, Toronto: Anchor Books; Doubleday, 1976)

17. G. Lakoff, M. Johnson, Philosophy in the Flesh (New York, NY: Basic Books, 1999)

18. Culturosity. The Costly (and Humorous) Impact of Cultural Blunders URL: http://www.culturosity.com/pdfs/CulturalBlunders.pdf>.

19. M. Fromowitz, Cultural blunders: Brands gone wrong. URL: https://www.campaignasia.com/article/cultural-blunders-brands-gonewrong/426043https://www.campaignasia.com/article/cultural-blunders-brands-gonewrong/426043

20. M. Fromowitz, Hall of shame: More multicultural brand blunders. URL: https://www.campaignlive.com/article/hall-shame-multicultural-brandblunders/1423941

21. T. Metcalf, Marketing Blunders \& Global Culture URL: https://smallbusiness.chron.com/marketing-blunders-global-culture-64855.html

22. A. Prykhodko, Concepts and Conceptual Systems in the Cognitive-Discursive Paradigm of Linguistics (Zaporizhya: Premier, 2008)

23. Creative translation: four examples of transcreation (good and bad) URL: https://www.translateplus.com/blog/creative-translation-four-examples-transcreationgood-bad/

24. K. Mulyk, M. Gumenny, On peculiarities of translating English advertising slogans into Ukrainian 29, 169-183 (Naukovyi visnyk KNPU im. K.D. Ushynskoho, 2019)

25. Truth in Advertising: $D D B$ and VW Encourage the World to Think Small URL: https://www.aaaa.org/timeline-event/vw-encourages-world-think-small/

26. Campaigns that changed the world URL: https://prhacker.com/today/campaigns/thinksmall-volkswagens/) 
27. Merriam

Webster

Dictionary

URL:

https://www.merriamwebster.com/dictionary/have $\% 20$ it $\% 20$ one $\% 27 \mathrm{~s} \% 20 \% 28$ own $\% 2$ 9\%20way

28. H. Masur, Strategic competence as a component determinant of professional competence of future translators 3 (122), 25-31 (Naukovyi visnyk KNPU im. K.D. Ushynskoho, 2018) 